\title{
AN APPROACH FOR MULTI-ATTRIB UTE FIRE RISK-AWARE EVALUATION OF BUILDING COMPONENTS
}

\author{
Grzegorz Ginda* \\ Opole University of Technology \\ Opole, Poland \\ E-mail: gginda@ gmail.com \\ Mariusz Maślak \\ Cracow University of Technology \\ Cracow, Poland \\ E-mail: mmaslak@pk.edu.pl
}

\begin{abstract}
Building objects are of a complex nature. Each building component can be implemented in many ways. Polish building regulations include different requirements with regard to structural, formal and functional solutions applied in buildings. They pertain to different features. Most of compulsory requirements pertain to tangible factors. However, there also appear intangible requirements which should be addressed too. Reliable identification of appropriate solutions requires therefore application of multi-attribute decision analysis. There is als o a group of requirements which relate to fire features. Elements of an approach which aims at multi-dimensional, intangibility-aware and fire features-aware evaluation of building solutions is presented. The approach comprises basis for future decision support system which is devoted to system selection of the most appropriate component alternative.
\end{abstract}

Keywords: building, component, material, feature, function, form, structure, fire, evaluation, multiple attributes, decision, evaluation, selection, support.

\section{Introduction}

Buildings consist of numerous components. The components are of different nature. Due to the building regulations, features of components applied in a building should ensure proper building exploitation in any anticipated condition. The regulations deal with safety, comfort, interrelations with surrounding environment of technical, economic, social and environmental nature. Requirements with regard to building and building components features are divided into groups which deal with distinct phases of life cycle: erection, normal operation, exceptional conditions and demolitions. Exceptional conditions deal also with the fire phase of building utilisation. Different stages of life cycle of building components makes their choice a complex multidimensional task.

Complexity of building components results also from combination of different component features and different features which correspond to different component functions. For example, there are components which serve structural purposes, some other serve finishing purposes. There are also components which serve both kinds of purposes.

Contemporary building regulations (The ordinance, 2002) deliver numerous requirements with regard to requirements for whole buildings, the ir parts and building components. The requirements are inter-related

\footnotetext{
${ }^{*}$ Corresponding author
} 
and are usually divided into several groups of related conditions. For example, Polish regulations include the following groups:

- general requirements with regard to a building, building interiors and vicinity influence of building usage on environment,

- equipment and safety for a building itself and its users,

- multi-dimiensional safety.

The safety requirements are further divided into several distinct classes:

- structural integrity,

- fire safety,

- buildings usage,

- health and lives of users,

- protection aga inst noise and trembling,

- energetic safety.

Distinction of fire safety requirements shows its importance as one of vital requirements for building users. Its importance results from fire threads and potentially severe consequences of fire situations for a building, lives and health of building users.

\section{Fire safety requirements}

Fire safety requirements pertain to:

- bearing capacity of a building structure and its components,

- fire spread restriction in the same building and nearby buildings,

- evacuation of building users,

- safety for fire fighters.

All these conditions are of strict nature i.e. building components are divided into several predefined resistance classes with regard to:

- bearing capacity $(\mathrm{R})$,

- fire tightness $(\mathrm{E})$,

- fire isolation (I).

The classes correspond to fire duration for which a component should preserve its properties. Time is given in minutes and is usually equal to integer multiplicity of 15 minutes. For example, R 120 means that a component should retain its bearing capacity during fire for at least 2 hours. Fire resistance requirements are defined for structural components (a general structure, a roof, a ceiling, an external and internal wall and a roof cover). Actual requirements depend on use of a building. Three building types are defined for this purpose:

1. Dwelling houses, collective habitation and public buildings (ZL).

2. Production buildings and storehouses (PM).

3. Stock buildings (IN).

Detailed conditions for components of buildings of the first type depend on its fire category of threads for people (depends on building usage) and a building he ight class. The lower category a building is the more sensitive to fire threads it is. The higher building is the more sensitive to fire threads it is. Higher sensitivity to fire level results in more severe requirements with regard to components. A fire resistance class can be reduced a little in the case of some buildings equipped with automat ic fire fighting devices. Division of buildings of the second type into fire categories of threads depends on a fire load and height of a building. Fire load expresses a combustion potential of applied equipment. Higher fire resistance requirements pertain to higher fire load value levels and the higher buildings. 
Fire resistance conditions of a building envelope e.g. roofs can also result from configuration and parameters of surrounding buildings.

Category of thread for people, a level of fire load and building height class influence requirements with regard to functional components of buildings e.g. permissible area of a fire zone or structure of fire separation partitions. Higher level of a fire load and higher buildings induce smaller admissible area of a fire zone. Permissible fire zone area is considerably restricted in the case of buildings for users with disabilities e.g small children, the elderly and ill people. Fire Enlargement of fire zone area is possible when additional automatic fire fighting devices operate inside a zone. Requirements with regard to structure of fire separation partitions result directly from category of a building.

Requirements with regard to efficient evacuation are strongly emphasised in existing building regulations. Required values of evacuation way parameters depend on type of a building, number of evacuated people, category of thread for users, fire load and additional threads e.g. risk of explosion, applied automatic fire fighting devices.

Existing regulations also include fire safety requirements to building finishing components. Application of a toxic and easily combustible stuff for finishing internal surfaces is prohibited in collective habitation and public buildings. Not only building components are addressed with this regard but also requirements with regard to applied equipment are formulated. Conditions for installations are discussed too.

Separate group of requirements deals with safe building location relative to existing building and infrastructural objects. Conditions with regard to multi-stand car garage buildings and their equipment are also discussed in the regulations. Stock buildings are separately addressed with this regard too.

Presented information with regard to fire safety of buildings and their components conf irms complexity of requirements present in the regulations.

\section{The Analysis of building components}

There is a continuous development in building technology. New materials and structural solutions appear. The portfolio of potentially applicable building solutions is continuously broadening. Multiplicity of available component alternatives which satisfy requirements of the regulations makes the problem of the most suitable component alternative choice rather a hard task.

There are other issues which make the choice even more difficult e.g. numerous and often conflicting requirements with regard to different functional, structural and formal aspects of application of building components. There are also various stakeholders engaged in decision making who declare different opinions i.e. investors, designers, contractors, supervisors, users etc. Sustainable and justified decision making also requires consideration of dimensions of non-technical, i.e. economic, social and environmental nature. There are also intangibles which result from inherited intangibility of considered objects and sometimes from imperfection of available information.

Application of an appropriate system approach which would include all above demands is therefore necessary to evaluate building components and identify the best of them. Essential issues with regard to proposal of such approach are presented in the next section.

\section{Addressing fire-risk aware issues}

\subsection{General issues}

Complex nature of building component causes that fire-risk aware analysis of available building components should deliver a broader view with regard to a complete set of important features. It should 
properly address various dimensions, stakeholder opinions and both tangible as well as intangible features of building components.

Prioritisation of considered objects with regard to tangible features is rather straightforward due to numerical evaluation. There can appear, however, issues with regard to imperfect information. There are several soft approaches available which are able to help including imperfect information successfully e.g. theory of fuzzy or rough sets.

Coping with intangibles is clearly more challenging issue. Application of AHP/ANP makes intangibility addressing considerably easier. It also delivers means for different interesting tasks e.g. gaining necessary information in the case of its incomplete nature or even lack.

Utilisation of AHP/ANP can serve several purposes in the case of fire risk-aware. For example, it allows to obtain qualitative information with regard to relative fire safety level provided by different building component alternatives, even if they nominally belong to the same fire resistance category. This is advantageous because even in the case small differences between component alternatives the best one can undoubtedly identified.

AHP/ANP proves very useful with regard to effective prioritisation of fire risk attributes (Zhu et al., 2004; Ginda, \& Maślak, 2006). Knowledge about fire building risk attributes can be thus acquired and immediately applied for evaluation of candidate building component alternatives. Concurrent application of AHP/ANP with regard to other intangible features and application of quantitative methods with regard to tangible features makes fire risk-aware analysis of available building components thorough, as intended.

It is also worth mentioning that group decision making mechanisms provided by AHP/ANP deliver means for adequate including of opinions provided by different stakeholders: investors, designers, contractors, (fire safety) inspectors and users. Utilisation of AHP/ANP also enables to include different dimensions of considered problems. Application of knowledge with regard to opinions of various stakeholders and analysis with regard to different dimensions allows to make more justif ied and conscious choices with regard to building components. They result in improvement of fire safety level of a building. AHP/ANP application isn't, however, particularly easy in the case of a decision making problem which involves considerable number of available alternatives. Ongoing research, though, makes evident that successful application of AHP/ANP is nevertheless possible in the case of large sets of evaluated objects thanks to utilisation of some vital extensions (Dytczak, \& Ginda 2011).

It is clear from above description that AHP/ANP comprises the proper tool for adequate addressing of problems and issues which were previously emphasised.

\subsection{Input data and data processing}

Successful application of the approach requires delivery of complete sets of data with regard to features of available building components. The data should be prepared for immediate utilisation. The ir suitable form therefore depends on applied procedures of data processing. Uniform structure of tangible and intangible data would allow also influence applied multi-attribute evaluation with regard to lowered complex ity and improvement in reliablity. Stimulative nature of non-negative scores (priorities) pertaining to different features is desired for each building component. Desired priority forms include:

- an idealised form (one for the best component alternative and a fraction of one for other alternatives),

- a normalised form (priorities for different component alternatives sum up to one),

- a unitarised form (priorities range from zero in the case of the worst component alternative to one in the case of the best component alternative).

The first two priority forms allow to obtain AHP/ANP rankings and the last form is the best suited for application of a cluster analysis. 
Raw tangible data are numeric and are therefore a lot easier to acquire and transform into mentioned priority forms. Preparation of data with regard to intangible component features require, however, additional effort. This is especially true in the case of presence of numerous available decision making alternatives (Dytczak, \& Ginda, 2011). Difference in acquisition procedures between tangible and intangible data result in the ir separate acquisition.

AHP/ANP is well suited for delivering importance weights for component features. Thus including feature importance differentiation can be introduced into evaluation of component alternatives. Derivation of weights requires opinions of an expert. Engagement of multiple and diverse experts is welcome with this regard to deliver justified values for the weights. A normalised importance weight data form is the most preferred due to desired application of additive and multiplicative simple weighting schemes

\subsection{Gene ral structure of the approach}

Provided data make obtaining of rankings and identification of component alternative clusters possible. Such information is very useful because it allows to obtain information about the most preferred or similarly preferred building component alternatives immediately. It is therefore important to equip a decision support system (DSS) system which would implement the approach with permanent and easily knowledge about results of applied data processing.

General scheme for the approach is presented in Fig.1. It can be considered the central part of a future DSS. It is therefore presented in a little wider DSS application-aware context.

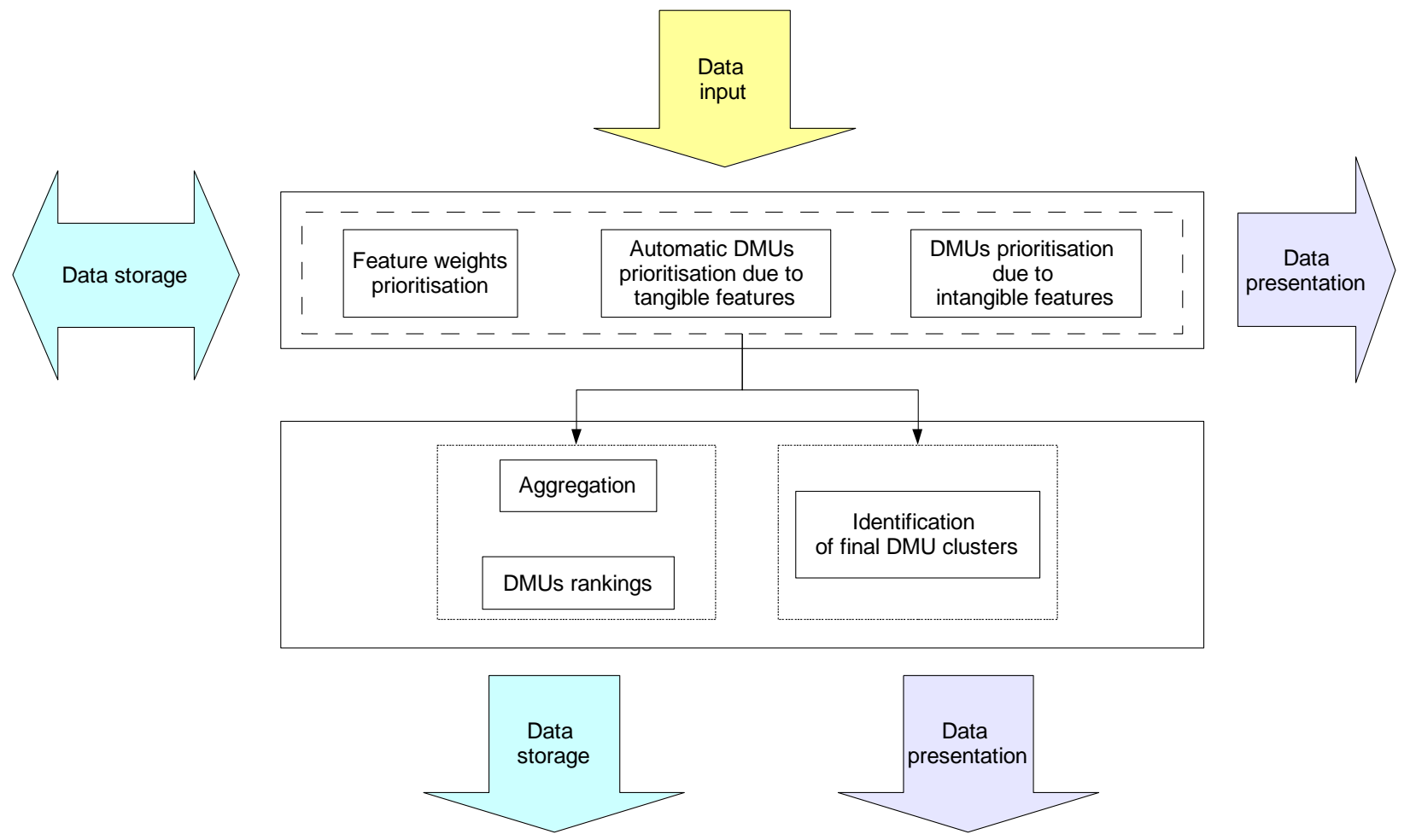

Figure 1. General scheme for the approach and its interrelations with DSS functions 


\section{Conclusions}

The proposed approach includes mechanisms which makes reliable and objective selection of appropriate building component alternative possible and transparent for decision maker. Its successful implementation, however, requires preparation of a complete database of component features and dimensions of the ir utilisation. The unique feature of the approach is devoted to wide embracement of building component fire safety among other important component features.

It seems that the approach would help to create a DSS which would make adaptation of the emerging building technology achievements easier and meeting all requirements including fire safety conditions. Preparation of decision support system which exploits the approach is underway. It is hoped to make process of identification of the best building component transparent to decision maker and objective.

\section{REFERENCES}

Dytczak, M., \& Ginda, G. (2011). Pair-wise comparison MCDA approach for large DMU sets. [In:] ISAHP 201 1. Proceedings, Sorrento, 15-18 June 2011.

Dytczak, M., \& Szklennik, N. (2011). Principles and applications of AHP/ANP-based multiple MCDA methods approach. [In:] ISAHP 2011. Proceedings, Sorrento, 15-18 June 2011.

Ginda, G., \& Maślak, M. (2006). Assessment of Factors Infuencing the Fire Safety For Building Users. [In:] Responding to Tomorrow's Challenges in Structural Engineering, IABSE Symposium, Budapest 2006, IABSE Report, vol.92, 2006, s. 260-261.

Zhao, C.M., \& Lo, S.M., Lu, J.A., \& Fang, Z. (2004). Fire Safety Journal, 39, 557-579.

Rozporządzenie Ministra Infrastruktury z dnia 12 kwietnia 2002 r. w sprawie warunków technicznych, jakim powinny odpowiadać budynki i ich usytuowanie [The Ordinance of Ministry for Infrastructure of Republic of Poland with regard to requirements pertaining to buildings and their vicinity] (2002). Dziennik Ustaw RP, No.75, point 690.

\section{ACKNOWLEDGEMENT}

This paper was elaborated with the financial support of the project granted by Polish Ministry of Science and Higher Education (N N506 243938). 